\title{
What's important to you? Socioeconomic inequalities in the perceived importance of health compared to other life domains
}

\author{
Sanne E. Verra ${ }^{1 *}$, Maartje P. Poelman², Andrea L. Mudd ${ }^{1}$, Emely de Vet ${ }^{2}$, Sofie van Rongen ${ }^{2}$, John de Wit ${ }^{1}$ and \\ Carlijn B.M. Kamphuis ${ }^{1}$
}

\begin{abstract}
Background: Pressing issues, like financial concerns, may outweigh the importance people attach to health. This study tested whether health, compared to other life domains, was considered more important by people in high versus low socioeconomic positions, with future focus and financial strain as potential explanatory factors.

Methods: A cross-sectional survey was conducted in 2019 among N=1,330 Dutch adults. Participants rated the importance of two health-related domains (not being ill, living a long life) and seven other life domains (e.g., work, family) on a five-point scale. A latent class analysis grouped participants in classes with similar patterns of importance ratings. Differences in class membership according to socioeconomic position (indicated by income and education) were examined using structural equation modelling, with future focus and financial strain as mediators.

Results: Three classes were identified, which were defined as: neutralists, who found all domains neutral or unimportant (3.5\% of the sample); hedonists, who found most domains important except living a long life, work, and religion (36.2\%); and maximalists, who found nearly all domains important, including both health domains (60.3\%). Of the neutralists, 38\% considered not being ill important, and 30\% considered living a long life important. For hedonists, this was $92 \%$ and $39 \%$, respectively, and for maximalists this was $99 \%$ and $87 \%$, respectively. Compared to belonging to the maximalists class, a low income predicted belonging to the neutralists, and a higher educational level and unemployment predicted belonging to the hedonists. No mediation pathways via future focus or financial strain were found.

Conclusions: Lower income groups were less likely to consider not being ill important. Those without paid employment and those with a higher educational level were less likely to consider living a long life important. Neither future focus nor financial strain explained these inequalities. Future research should investigate socioeconomic differences in conceptualisations of health, and if inequalities in the perceived importance of health are associated with inequalities in health. To support individuals dealing with challenging circumstances in daily life, health-promoting interventions could align to the life domains perceived important to reach their target group and to prevent widening socioeconomic health inequalities.
\end{abstract}

\footnotetext{
*Correspondence: s.e.verra@uu.nl

1 Department of Interdisciplinary Social Science, Utrecht University,

Padualaan 14, $3584 \mathrm{CH}$ Utrecht, the Netherlands

Full list of author information is available at the end of the article
}

\section{Background}

Health inequalities are widening, even in countries with elaborate welfare systems [1]. Those with a lower socioeconomic position (SEP) often face unfavourable material and psychosocial conditions $[2,3]$. The accumulation of material and psychosocial risk factors contributes to large inequalities in health. In the Netherlands, this 
translates to an average gap of eighteen healthy life years between those with a lower and higher SEP [4]. Alongside material and environmental factors, a part of these health inequalities results from differences in health behaviour $[1,5,6]$.

A potential explanation for socioeconomic inequalities in health is that taking care of one's health may be less prominent in the lives of those with a lower SEP compared to those with a higher SEP [7]. Health is often considered a universal value [8]. Yet, several studies showed that when comparing the importance of health to other life domains, it is not given equal weight by everyone [9-12]. Schneider and Barnes (2003) analysed the importance of different life goals as motivators for decisionmaking and found that health was generally identified as less important than other goals, such as relationships and careers [10]. In daily life, health competes with many other priorities, such as work and social obligations. Other priorities frequently outweigh the perceived importance of health [9].

One reason it may be difficult to prioritise health over other life domains is that health behaviours mainly pay off in the future, whereas investments in other life domains, such as spending time with friends, result in more immediate benefits. Studies have shown that those with a lower SEP tend to focus more on the present than those with a higher SEP [13, 14]. Having a future focused orientation instead of a focus on the present has been linked to healthier dietary behaviour [15] and could mediate socioeconomic inequalities in the perceived importance of health.

Financial strain is another potential mediator of the relationship between SEP and the importance of health. Scarcity theory posits that the stress to make ends meet may take up a lot of cognitive capacity, leaving little capacity to deal with less urgent matters [1618]. Although an increased focus on pressing issues like financial strain helps in dealing with the current situation, a less urgent and more long-term goal such as staying healthy may receive less attention [16]. As a result, the perceived importance of health compared to other life domains could be lower among those with a lower SEP compared to those with a higher SEP, as those with a lower SEP are more likely to experience financial strain [19].

Inequalities in the perceived importance of health compared to other life domains are understudied $[8,9,20]$. We hypothesize that people with a lower SEP are more likely than people with a higher SEP to perceive health as less important compared to other life domains (such as financial situation, work or leisure time). Explanations may be that people with a lower SEP are less likely to have a future focused orientation, or that challenging issues in other life domains could outweigh the perceived importance of health. The aims of this study are: (1) to identify if and to what extent there are socioeconomic inequalities in the perceived importance of health compared to other life domains, and (2) to what extent these socioeconomic inequalities in the perceived importance of health are mediated by future focus and financial strain.

\section{Methods}

\section{Design and study population}

A cross-sectional survey was undertaken in January 2019. Participants were recruited from a panel established by an online research agency [21]. Individuals between 25 and 60 years old who were not enrolled in education could participate. The survey was completed by 1,336 participants $(59 \%$ response rate, mean age $=44.8, \mathrm{SD}=$ $10.4,57 \%$ female, $95 \%$ identified as Dutch). Lower income panel members were oversampled to compensate for their potential relatively lower response rate [22, 23]. This led to the inclusion of 531 low, 404 middle, and 401 high income participants. Two cases with missing values for gender were excluded, as well as four cases with a missing value for educational level, resulting in an analytical sample of $N=1,330$. The sample was representative of the Dutch population with regards to gender, age, educational level, and province but not income [24]. Compared to the income distribution in the Dutch population, lower incomes were overrepresented in our sample [25]. Ethical approval was obtained from the ethics committee of the faculty of Science and Geo Sciences of Utrecht University (GEO FETC18-014).

\section{Measures}

\section{Socioeconomic position}

Income and education were used as separate indicators of SEP, as both measure different aspects of SEP [26]. The online research agency supplied data on gross household income of participating panel members, categorised as low $(<€ 13.300$ per year), middle $(€ 13.300$ - $€ 41.200)$, and high ( $₫ € 41.200$ per year). Participants reported their highest completed level of education in the survey. Following ISCED 2011 classifications, education was categorised as low (lower secondary education at most; ISCED $0-2$ ), middle (upper secondary education; ISCED 3-4), or high (tertiary education; ISCED 5-6).

\section{Importance of health compared to other life domains}

Based on the approach by Hsieh, [11] participants rated the importance of nine items representing life domains on a five-point Likert scale ( $1=$ "very unimportant", $5=$ "very important"): work, spare time, financial situation, neighbourhood, family life, friendships, religion, and two health domains. We included two health domains, 
since a Dutch qualitative study [27] found those with a lower education more likely to conceptualise health in mostly negative terms (e.g., "absence of disease"), while the more highly educated also included more positive aspects, such as "lust for life" and "vitality". To account for possible differences in the conceptualisation of health, the importance of two distinct health-related items was assessed: "not being ill" (a negative frame) and "living a long life" (a positive frame). For all nine items, the fivepoint Likert scale answers were dichotomised ("very unimportant", "unimportant", and "neutral" categorized as unimportant, and "important" and "very important" categorized as important) to improve interpretability of the latent class analysis (LCA) results (explained under statistical analysis).

\section{Future focus}

Future focus was measured using the Temporal Focus Scale [28]. Four future-focused items, for example, "My mind is on the here and now" and "I think about what my future has in store" (Cronbach's $\alpha=0.86$ ), were included. Participants answered on a five-point scale $(1=$ "never", 5 $=$ "constantly"). Based on the average scores across items, three categories were created: low (mean score $\leq 2$ ), middle (>2 and $\leq 3)$, and high $(>3)$ future orientation.

\section{Financial strain}

Financial strain was assessed with six items (Cronbach's $\alpha=0.95)$. To create a combined financial strain measure, the answer categories of each financial strain item were divided into low, medium, and high financial strain. Two items asked about financial strain in the preceding year: "Have you experienced difficulty paying for your food, rent, and bills from your household income?" with responses considered as low ("no difficulty"), medium ("some difficulty"), or high ("a lot of difficulty"), and "How is your household getting by?" with four response options, considered as low ("easily", "somewhat easily"), medium ("with some difficulty"), and high ("with large difficulty"). Four items asked about daily financial strain, for example: "How often in the last four weeks did you worry about your financial situation?", measured on a five-point scale. Responses were considered as low ("never" and "rarely"), medium ("sometimes"), and high ("often" and "constantly"). Participants were assigned a low, medium or high financial strain ranking based on their highest answer (low, medium or high) across the six items.

\section{Potential confounders}

Age, gender, and paid employment were included as confounders, as previous research pointed to their influence in the perceived importance of life domains, [10,
12,29] and they have been associated with SEP. Age was included as a continuous variable and gender as a binary variable $(1=$ female, $0=$ male). Paid employment was assessed as a binary variable $(1=$ in paid employment, 0 $=$ not in paid employment). Paid employment status was not used as an indicator of SEP since it does not capture what occupational class the person is employed in [30].

\section{Statistical analysis}

This study assessed the perceived importance rating of the different life domains using a LCA. The outcome of the LCA, or "class membership", was used as dependent variable in subsequent models.

The LCA distributed participants in classes based on patterns in their importance ratings of the nine life domains. Different LCA models were tested, predicting two to six classes. To find the amount of classes with the highest likelihood, 5,000 iterations were run with 30 different starting values for each model. To choose the optimal number of classes, we drew on the Bayesian Information Criterion (BIC), a model fit measure that penalises model complexity more than the Akaike Information Criterion (AIC) [31]. No data were missing in this part of the analysis. Each participant was assigned to the class for which their membership probability was largest $[32,33]$. The LCA was conducted in R, using poLCA version 1.4.1 [34].

A structural equation model (SEM) was built to examine whether future focus and financial strain mediated the relationship between SEP and class membership. The approach used by Nguyen et al. [35] was followed, as this allowed for multiple ordinal mediators and binary outcomes. Predictors included income and educational level as indicators of SEP, future focus and financial strain as mediators, and age, gender and employment as confounders. The step-by-step procedure from Zhao et al. was used to test for mediation [36]. The SEM with probit link used a Weighted Least Square Mean and Variance adjusted estimator and was run in Mplus version 8.4 [37].

\section{Results}

\section{Latent Class Analysis}

Model fit statistics of the LCA showed that the threeclass model had the most optimal BIC value (see Table 1). This model allowed for the classification of participants into three meaningful classes: (1) neutralists, who were likely to rate all domains neutral or unimportant (3.5\% of the sample, $n=47)$, (2) hedonists, who were likely to find many domains important, except for living a long life, work, and religion $(36.2 \%, \mathrm{n}=482)$, and (3) maximalists, who were likely to find all life domains important, except religion $(60.3 \%, \mathrm{~N}=802)$. Note that the names used to describe the three classes were based on the researchers' 
Table 1 Key statistics for different LCA models

\begin{tabular}{llllc}
\hline Classes & Log- likelihood & $\begin{array}{l}\text { Degrees of } \\
\text { freedom }\end{array}$ & BIC & AIC \\
\hline 2 & $-4,925.314$ & 492 & $9,987.295$ & $9,888.629$ \\
3 & $-4,842.475$ & 482 & $9,893.545$ & $9,742.950$ \\
4 & $-4,822.027$ & 472 & $9,924.578$ & 9.722 .053 \\
5 & $-4,808.963$ & 462 & $9,970.380$ & $9,715.926$ \\
6 & $-4,793.674$ & 452 & $10,011.73$ & $9,705.348$ \\
\hline
\end{tabular}

interpretation of the characteristics of the mentioned classes.

Figure 1; Table 2 depict how health and other life domains were rated by the different classes. Overall, those in the neutralists class rated all domains neutrally important, including both health domains. The domains that neutralists most often rated important were not being ill (rated important by $38 \%$, see Table 2), financial situation (rated important by $34 \%$ ), and family (rated important by $21 \%$ ). Least important to neutralists were religion (rated important by $4 \%$ ), work (rated important by $4 \%$ ), and friendships (rated important by $11 \%$ ).

Those in the hedonists class were more likely to rate life domains important than those in the neutralists class. The domains that hedonists rated most often important were not being ill (rated important by $92 \%$ ), spare time (rated important by $85 \%$ ), and financial situation (rated important by $79 \%$ ). Least important to hedonists were religion (rated important by $23 \%$ ), work (rated important by $37 \%$ ), and living a long life (rated important by $39 \%$ ).

Those in the maximalists class were more likely to rate life domains important than those in the neutralists and hedonists classes. The domains maximalists rated most often important were family (rated important by $100 \%$ ), spare time (rated important by $100 \%$ ), and not being ill (rated important by 99\%). Least important to maximalists were religion (rated important by $32 \%$ ), work (rated important by $79 \%$ ), and living a long life (rated important by $87 \%)$.

All classes rated not being ill as most important compared to the other life domains, yet the probability of perceiving not being ill important was lower for neutralists and hedonists compared to maximalists. The hedonists and the maximalists considered living a long life as one of the least important life domains. Relatively, living a long life was considered similarly important as the other life domains for those in the maximalists and neutralists classes, but living a long life was considered substantially less important than other life domains among those in the hedonists class.

Table 2 shows the demographic characteristics of participants in each class. Compared to the other classes, those in the neutralists class were most likely to have a low educational level, low income level, no paid employment, to be less future focused, and to experience high financial strain. Those in the hedonists class were most likely to have a middle educational level, and to belong to the middle income category. Those in the hedonists class were also less likely to have paid employment, to be future focused, and more likely to experience financial strain compared to those in the maximalists class.

SEMs were built for two outcome variables: predicting the probability of belonging to the neutralists class compared to the maximalists class and predicting the probability of belonging to the hedonists class compared to the maximalists class. As those in the maximalists class had the highest overall domain ratings, this was used as reference class. The SEMs were built in three steps, by including (1) income and education; (2) confounders, and (3) mediators. This resulted in a total of six SEMs. Table 3 presents the main model results. Note that only the effects for class membership and mediators as dependent variables are presented. More effects (such as the influence of the confounders on our SEP variables, and the relationship between our SEP variables) were estimated in the models, but excluded from Table 3. See Supplementary File 1 for a graphical representation of all relationships estimated in model 3.

Results from the first models showed that a higher income decreased the likelihood of belonging to the neutralists or hedonists classes compared to the maximalists class (Table 3, models 1). Level of education did not significantly influence class membership. While controlling for confounders (Table 3, models 2), the effect of income decreased but remained significant for both classes compared to those in the maximalists class. The effect of education remained insignificant.

When introducing the mediators (Table 3, models 3 ), the income effect persisted for those in the neutralists class but disappeared for those in the hedonists class, both compared to those in the maximalists class. Instead, those with a higher level of education were significantly more likely to belong to the hedonists class compared to the maximalists class. Having a future focus was negatively associated with the likelihood of belonging to either the neutralists or hedonists classes compared to the maximalists class, but future focus was not associated with income or educational level. Yet, the influence of having a future focus on class membership was stronger that the effects of the SEP variables on class membership. Financial strain was negatively associated with income but was not associated with class membership. No mediation effects were tested, since neither future focus or financial strain fulfilled the requirement of being associated with both 

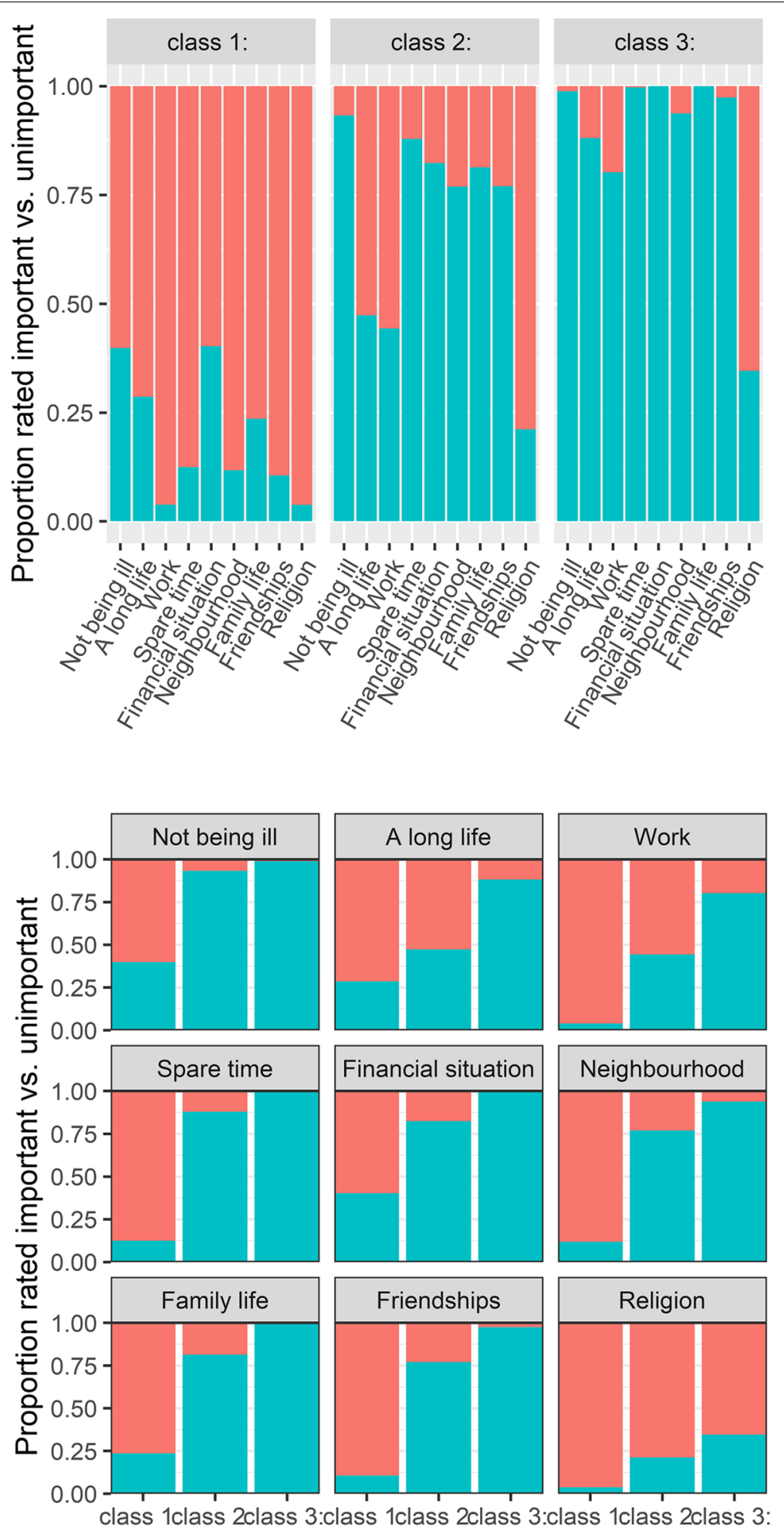

Fig. 1 The proportion of life domains considered important vs. unimportant per class (above) and per life domain (below). Class 1: neutralists, class 2: hedonists, class 3: maximalists 
Table 2 Sample characteristics by class membership

\begin{tabular}{|c|c|c|c|c|c|c|}
\hline & & $\begin{array}{l}\text { Total } \\
N=1,330\end{array}$ & $\begin{array}{l}\text { Neutralists } \\
(n=47)\end{array}$ & $\begin{array}{l}\text { Hedonists } \\
(\mathrm{n}=482)\end{array}$ & $\begin{array}{l}\text { Maximalists } \\
(\mathrm{n}=\mathbf{8 0 1})\end{array}$ & $\begin{array}{l}X^{2} \\
\text { statistic }^{\mathrm{a}}\end{array}$ \\
\hline \multirow[t]{3}{*}{ Education } & Low & $27 \%$ & $45 \%$ & $26 \%$ & $26 \%$ & \multirow{3}{*}{$\begin{array}{l}11.11 \\
*\end{array}$} \\
\hline & Middle & $46 \%$ & $40 \%$ & $48 \%$ & $45 \%$ & \\
\hline & High & $27 \%$ & $15 \%$ & $26 \%$ & $29 \%$ & \\
\hline Yearly & $<€ 13,300$ & $40 \%$ & $79 \%$ & $45 \%$ & $34 \%$ & 58.72 \\
\hline household & $€ 13,300-41,200$ & $30 \%$ & $19 \%$ & $32 \%$ & $30 \%$ & \multirow[t]{2}{*}{$* * *$} \\
\hline income & $>€ 41,200$ & $30 \%$ & $2 \%$ & $23 \%$ & $36 \%$ & \\
\hline \multirow[t]{4}{*}{ Age } & $25-35$ & $22 \%$ & $13 \%$ & $21 \%$ & $23 \%$ & 4.67 \\
\hline & $35-45$ & $24 \%$ & $28 \%$ & $23 \%$ & $24 \%$ & \multirow[t]{3}{*}{ ns } \\
\hline & $45-55$ & $32 \%$ & $40 \%$ & $32 \%$ & $32 \%$ & \\
\hline & $55-60$ & $23 \%$ & $19 \%$ & $24 \%$ & $22 \%$ & \\
\hline \multirow[t]{2}{*}{ Gender } & Female & $57 \%$ & $68 \%$ & $56 \%$ & $58 \%$ & 2.47 \\
\hline & Male & $43 \%$ & $32 \%$ & $44 \%$ & $42 \%$ & ns \\
\hline Employment & Paid & $63 \%$ & $36 \%$ & $52 \%$ & $71 \%$ & 62.36 \\
\hline status & Other & $37 \%$ & $64 \%$ & $48 \%$ & $29 \%$ & $* * *$ \\
\hline \multirow[t]{2}{*}{ Ethnicity } & Dutch & $95 \%$ & $96 \%$ & $95 \%$ & $95 \%$ & 0.32 \\
\hline & Non-Dutch & $5 \%$ & $4 \%$ & $5 \%$ & $5 \%$ & ns \\
\hline \multirow[t]{3}{*}{ Future focus } & Low & $4 \%$ & $11 \%$ & $6 \%$ & $3 \%$ & 39.18 \\
\hline & Middle & $35 \%$ & $47 \%$ & $42 \%$ & $31 \%$ & \multirow[t]{2}{*}{$* * *$} \\
\hline & High & $61 \%$ & $42 \%$ & $52 \%$ & $66 \%$ & \\
\hline Financial & Low & $18 \%$ & $8 \%$ & $17 \%$ & $20 \%$ & 16.02 \\
\hline \multirow[t]{2}{*}{ strain } & Middle & $33 \%$ & $28 \%$ & $29 \%$ & $35 \%$ & \multirow[t]{2}{*}{$* *$} \\
\hline & High & $49 \%$ & $64 \%$ & $54 \%$ & $45 \%$ & \\
\hline \multirow[t]{2}{*}{ Not being ill } & Important & $94 \%$ & $38 \%$ & $92 \%$ & $99 \%$ & \multirow{2}{*}{$\begin{array}{l}308.66 \\
* * *\end{array}$} \\
\hline & Unimportant & $6 \%$ & $62 \%$ & $8 \%$ & $1 \%$ & \\
\hline Living a long & Important & $68 \%$ & $30 \%$ & $39 \%$ & $87 \%$ & 341.93 \\
\hline life & Unimportant & $32 \%$ & $70 \%$ & $61 \%$ & $13 \%$ & $* * *$ \\
\hline \multirow[t]{2}{*}{ Spare time } & Important & $91 \%$ & $11 \%$ & $85 \%$ & $100 \%$ & \multirow{2}{*}{$\begin{array}{l}487.06 \\
* * *\end{array}$} \\
\hline & Unimportant & $9 \%$ & $89 \%$ & $15 \%$ & $0 \%$ & \\
\hline \multirow[t]{2}{*}{ Financial situation } & Important & $90 \%$ & $34 \%$ & $79 \%$ & $100 \%$ & \multirow{2}{*}{$\begin{array}{l}319.60 \\
* * *\end{array}$} \\
\hline & Unimportant & $10 \%$ & $66 \%$ & $21 \%$ & $0 \%$ & \\
\hline \multirow[t]{2}{*}{ Family } & Important & $89 \%$ & $21 \%$ & $77 \%$ & $100 \%$ & \multirow{2}{*}{$\begin{array}{l}386.48 \\
* * *\end{array}$} \\
\hline & Unimportant & $11 \%$ & $79 \%$ & $23 \%$ & $0 \%$ & \\
\hline \multirow[t]{2}{*}{ Friendships } & Important & $85 \%$ & $11 \%$ & $68 \%$ & $100 \%$ & \multirow{2}{*}{$\begin{array}{l}456.96 \\
* * *\end{array}$} \\
\hline & Unimportant & $15 \%$ & $89 \%$ & $32 \%$ & $0 \%$ & \\
\hline \multirow[t]{2}{*}{ Neighbour-hood } & Important & $83 \%$ & $9 \%$ & $73 \%$ & $94 \%$ & \multirow{2}{*}{$\begin{array}{l}293.62 \\
* * *\end{array}$} \\
\hline & Unimportant & $17 \%$ & $91 \%$ & $27 \%$ & $6 \%$ & \\
\hline \multirow[t]{2}{*}{ Work } & Important & $61 \%$ & $4 \%$ & $37 \%$ & $79 \%$ & \multirow{2}{*}{288.81} \\
\hline & Unimportant & $39 \%$ & $96 \%$ & $63 \%$ & $21 \%$ & \\
\hline Religion & Important & $27 \%$ & $4 \%$ & $23 \%$ & $32 \%$ & 24.76 \\
\hline & Unimportant & $73 \%$ & $96 \%$ & $77 \%$ & $68 \%$ & ${ }^{* * *}$ \\
\hline
\end{tabular}

${ }^{a}$ Significance levels are reported based on ${ }^{*} p<0.05,{ }^{* *} p<0.01,{ }^{* * *} p<0.001$

the predictor (SEP) and the outcome (class membership). None of the confounders predicted belonging to the neutralists vs. maximalists class. Not being in paid employment and being male predicted belonging to the hedonists vs. maximalists class, the effects of these confounders exceeded the influence of education and income. 
Table 3 Results of structural equation models

\begin{tabular}{|c|c|c|c|c|}
\hline & Outcome & Predictors & $\begin{array}{l}\text { Neutralists vs. } \\
\text { Maximalists }^{\mathrm{a}}\end{array}$ & $\begin{array}{l}\text { Hedonists vs. } \\
\text { Maximalists }\end{array}$ \\
\hline \multirow[t]{3}{*}{ Model 1: Income and educational level } & Class membership & Income & $-0.68(0.14)^{* * *}$ & $-0.23(0.05)^{* * *}$ \\
\hline & & Education & $-0.09(0.11)$ & $0.05(0.05)$ \\
\hline & $\mathrm{CFI}^{\mathrm{b}}$ & & 1.00 & 1.00 \\
\hline \multirow[t]{6}{*}{ Model 2: Model $1+$ confounders } & Class membership & Income & $-0.47(0.11)^{* * *}$ & $-0.11(0.04)^{*}$ \\
\hline & & Education & $0.01(0.10)$ & $0.09(0.05)$ \\
\hline & & Employment & $-0.15(0.20)$ & $-0.41(0.10)^{* * *}$ \\
\hline & & Age & $-0.00(0.01)$ & $0.00(0.01)$ \\
\hline & & Gender & $-0.20(0.18)$ & $-0.19(0.08)^{*}$ \\
\hline & CFI & & 0.89 & 0.89 \\
\hline \multirow[t]{19}{*}{ Model 3: Model 2 + mediators } & Class membership & Income & $-0.52(0.14)^{* * *}$ & $-0.09(0.05)$ \\
\hline & & Education & $0.00(0.11)$ & $0.10(0.05)^{*}$ \\
\hline & & Financial strain & $-0.08(0.11)$ & $0.03(0.05)$ \\
\hline & & Future focus & $-0.30(0.09)^{* *}$ & $-0.22(0.05)^{* * * *}$ \\
\hline & & Employment & $-0.10(0.20)$ & $-0.37(0.10)^{* * *}$ \\
\hline & & Age & $-0.01(0.01)$ & $-0.00(0.00)$ \\
\hline & & Gender & $-0.16(0.19)$ & $-0.17(0.08)^{*}$ \\
\hline & Future focus & Income & $0.02(0.04)$ & $0.02(0.04)$ \\
\hline & & Education & $0.03(0.04)$ & $0.03(0.04)$ \\
\hline & & Employment & $0.20(0.09)^{*}$ & $0.20(0.09)^{*}$ \\
\hline & & Age & $-0.02(0.00)^{* * *}$ & $-0.02(0.00)^{* * *}$ \\
\hline & & Gender & $0.15(0.07)^{*}$ & $0.15(0.07)^{*}$ \\
\hline & Financial strain & Income & $-0.49(0.05)^{* * *}$ & $-0.49(0.05)^{* * *}$ \\
\hline & & Education & $-0.03(0.04)$ & $-0.03(0.04)$ \\
\hline & & Employment & $-0.10(0.09)$ & $-0.11(0.09)$ \\
\hline & & Age & $0.00(0.00)$ & $0.00(0.00)$ \\
\hline & & Gender & $0.07(0.07)$ & $0.07(0.07)$ \\
\hline & Financial strain with & Future focus & $0.07(0.04)$ & $0.07(0.04)$ \\
\hline & CFI & & 0.92 & 0.92 \\
\hline
\end{tabular}

a Probit coefficients, standard errors in parentheses, significance level are reported based on ${ }^{*} p<0.05,{ }^{* *} p<0.01,{ }^{* * *} p<0.001$

${ }^{\mathrm{b}}$ Comparative Fit Index (CFI)

\section{Discussion}

This study identified subtle socioeconomic inequalities in the perceived importance of health compared to other life domains, which could not be explained by future focus or financial strain. Based on the importance attached to health (assessed as not being ill and living a long life) and seven other life domains, we identified three latent classes: (1) those in the neutralists class considered health and other life domains mostly neutral or unimportant, (2) those in the hedonists class considered most life domains important, with the exception of living a long life, work, and religion, and (3) those in the maximalists class considered living a long life and not being ill important, as well as most other life domains.

Income inequalities in the importance of health compared to other life domains were identified in nearly all models (a low income increased the likelihood of belonging to the neutralists vs. maximalists class and thus considering not being ill less important), and educational inequalities were identified in one model (a higher educational level increased the likelihood of belonging to the hedonists vs. maximalists class and thus considering living a long life less important). To our knowledge, only one previous study by Bowling [12] also assessed a social gradient in the importance of health (though only based on descriptive statistics). Bowling found a trend according to occupational level (those in low occupational classes were somewhat more likely to mention their own health as the most important thing in life than those in the highest occupational class), but identified no consistent trend according to income or education. [12].

Having a lower income and low future focus increased the likelihood of belonging to the neutralists vs. maximalists class. Participants in the neutralists class may 
have been fully pre-occupied by their challenging circumstances, which may explain their indifferent or somewhat negative stance on the importance of not being ill and various other life domains [38]. This indifference may also function as a coping strategy for dealing with multiple disadvantages [39]. Another explanation could be that people with lower incomes are more frequently ill, which could normalize being ill, and result in a lower perceived importance of not being ill compared to other life domains. However, neither future focus nor financial strain could explain these socioeconomic inequalities in the importance of health and other life domains. Although associated with the importance of health and other life domains, future focus was not linked to the SEP indicators (education nor income) in this sample. The relatively high prevalence of financial strain in all three classes might explain why it was not identified as an explanatory factor for class membership.

In addition to the socioeconomic effects, being in paid employment also had a substantial influence on the importance of health and other life domains. Having no paid or unpaid employment has been associated with many stressors and a depletion of financial and social resources [40]. The associated decrease in social participation [41] combined with the stress of being unemployed could lead to a general feeling of disengagement [40], which could explain the lower importance ratings among those in the hedonists class compared to those in the maximalists class. The strong influence of employment might also partially capture the effect of health status on the perceived importance of living a long life, as people might be excluded from work due to their health status [26]. Several strengths and limitations should be raised. Most importantly, findings from this study cannot be causally interpreted since cross-sectional data was used. It remains possible that class membership impacted the mediators and SEP in the opposite direction. To be able to draw a causal conclusion about the relationship between SEP and the perceived importance of health compared to other life domains, the findings of this study need to be followed up with a longitudinal study. Moreover, our sample was stratified based on income to ensure a high representation of those with lower incomes, while keeping the sample representative of the Dutch population for education, age, gender, and province. This is a strength because those with lower incomes are often underrepresented, even in research on socioeconomic inequalities. Yet, as a result of the oversampling of low income participants, the effect size of income may have been slightly amplified. We anticipate that a lower income would also be associated with a lower perceived importance of health in the Dutch population. Our survey used a selection of life domains based on Hsieh [11].
This selection may not have reflected important life domains for all participants. Qualitative research into the position of health compared to other life domains and its interpretation may shed more light on this, since explanations for the identified socioeconomic inequalities could also point to socioeconomic differences in reference points or views towards health. Moreover, a reliable statistical method to examine nominal latent outcome variables and multiple mediators has yet to be developed [42]. Therefore, the latent class variable was treated as known, which may have caused downward bias in estimates [43].

Future research could look into other explanations for socioeconomic inequalities in the perceived importance of health. Interesting pathways could include the role of class environment or changes in socioeconomic position or health status. Furthermore, it remains to be studied if socioeconomic inequalities in the perceived importance of health translate into socioeconomic inequalities in health.

\section{Conclusions}

Lower income groups were less likely to consider not being ill important than higher income groups. Those without paid employment and those with a higher educational level were less likely to consider living a long life important than those in lower educational level and those in paid employment. Furthermore, it was noticeable that people with a lower income were less likely to consider any of the included life domains important. Future research should examine if this has detrimental consequences for their (mental) health. Neither future focus nor financial strain contributed to the explanation of the socioeconomic inequalities in the perceived importance of health and other life domains. To support individuals dealing with challenging circumstances in daily life, health-promoting interventions could align to the life domains perceived important to reach their target group and to prevent widening socioeconomic inequalities in health.

\section{Abbreviations \\ SEP: Socioeconomic position; ISCED: International Standard Classification of Education; LCA: Latent Class Analysis; BIC: Bayesian Information Criterion; AIC Akaike Information Criterion; SEM: structural equation model; CFI: Compara- tive Fit Index.}

\section{Supplementary Information}

The online version contains supplementary material available at https://doi. org/10.1186/s12889-022-12508-2.

Additional file 1. 


\section{Acknowledgements}

The authors would like to thank Peter Lugtig for his valuable methodological advice.

\section{Authors' contributions}

SEV, MPP, JdW, and CBMK conceived the idea for the research questions and study design. MPP, CBMK, EdV and SvR designed the survey and collected the data. SEV carried out the analyses and drafted the first version of the manuscript. All authors contributed to the interpretation of the findings and critically revised the manuscript. All authors read and approved the final manuscript.

\section{Funding}

This research was funded by the Innovational Research Incentives Schemes of The Netherlands Organization for Scientific Research (NWO). SEV, ALM, and CBMK were supported by NWO's Innovational Research Incentives Scheme, VIDI grant number 198-001. Data collection of this research was funded by NWO grants awarded to EdV, VIDI grant number 452-14-014, and MPP, VENI grant number 451-16-029. The funding body was not in any way involved in the design of the study, data collection, analysis, interpretation of data, and the writing of the manuscript.

\section{Availability of data and materials}

The datasets used and/or analyzed during the current study are available from the corresponding author on reasonable request.

\section{Declarations}

\section{Ethics approval and consent to participate}

All procedures involving human participants were carried out in accordance with the ethical standards of the institutional and/or national research committee (Utrecht University, Faculty of Science and Geo Sciences Ethics Board GEO FETC \#18-014) and with the 1964 Helsinki declaration and its later amendments or comparable ethical standards. The study received ethical approval from Utrecht University's Faculty of Science and Geo Sciences Ethics Board (GEO FETC \#18-014). Informed consent was obtained from all individual participants included in the study.

\section{Consent for publication}

Not applicable.

\section{Competing interests}

The authors declare that they have no competing interests.

\section{Author details}

'Department of Interdisciplinary Social Science, Utrecht University, Padualaan 14, $3584 \mathrm{CH}$ Utrecht, the Netherlands. ${ }^{2}$ Chair group Consumption and Healthy Lifestyles, Wageningen University \& Research, Hollandseweg 1, 6706 KN Wageningen, the Netherlands.

Received: 7 September 2021 Accepted: 29 December 2021 Published online: 13 January 2022

\section{References}

1. Mackenbach JP. The persistence of health inequalities in modern welfare states: The explanation of a paradox. Soc Sci Med. 2012;75(4):761-9.

2. Lynch JW, Smith GD, Kaplan GA, House JS. Income inequality and mortality: importance to health of individual income, psychosocial environment, or material conditions. BMJ. 2000;320(7243):1200

3. Phelan JC, Link BG, Tehranifar P. Social Conditions as Fundamental Causes of Health Inequalities: Theory, Evidence, and Policy Implications. J Health Soc Behav. 2010;51(1_suppl):S28-40.

4. RIVM. Gezondheidsverschillen | Volksgezondheid Toekomst Verkenning [Health Inequalities. Public Health Foresight Study] [Internet]. 2018 [cited 2021 Sep 6]. Available from: https://www.vtv2018.nl/gezondheidsvers chillen
5. Vineis P, Avendano-Pabon M, Barros H, Bartley M, Carmeli C, Carra L, et al. Special Report: The Biology of Inequalities in Health: The Lifepath Consortium. Front Public Health. 2020;8.

6. Oude Groeniger J, Kamphuis CB, Mackenbach JP, van Lenthe FJ. Repeatedly measured material and behavioral factors changed the explanation of socioeconomic inequalities in all-cause mortality. J Clin Epidemiol. 2017;91:137-45.

7. Wink G, Fransen G, Huisman M, Boersma S, van Disseldorp L, van der Velden K, et al. 'Improving Health through Reducing Stress': Parents' Priorities in the Participatory Development of a Multilevel Family Health Programme in a Low-Income Neighbourhood in The Netherlands. Int J Environ Res Public Health. 2021;18(15):8145.

8. Smith MS, Wallston KA. How to measure the value of health. Health Educ Res. 1992;7(1):129-35.

9. Hughner RS, Kleine SS. Views of Health in the Lay Sector: A Compilation and Review of How Individuals Think about Health. Health (N Y). 2004;8(4):395-422.

10. Schneider SL, Barnes MD. What Do People Really Want? Goals and Context in Decision Making. In: Schneider SL, Shateau J, editors. Emerging Perspectives on Judgement and Decision Research. Cambridge: Cambridge University Press; 2003. p. 394-428.

11. Hsieh C-M. Importance is Not Unimportant: The Role of Importance Weighting in QOL Measures. Soc Indic Res. 2012;109(2):267-78.

12. Bowling A. What things are important in people's lives? A survey of the public's judgements to inform scales of health related quality of life. Soc Sci Med. 1995;41(1):1447-62.

13. Wardle J, Steptoe A. Socioeconomic differences in attitudes and beliefs about healthy lifestyles. J Epidemiol Community Health. 2003;57(6):440.

14. Fuchs VR. Time Preference and Health: An Exploratory Study. In: Time Preference and Health: An Exploratory Study [Internet]. University of Chicago Press; 2008 [cited 2021 Nov 16]. p. 93-120. Available from: https://www. degruyter.com/document/doi/10.7208/9780226267944-005/html

15. Dassen FCM, Houben $K$, Jansen A. Time orientation and eating behavior: Unhealthy eaters consider immediate consequences, while healthy eaters focus on future health. Appetite. 2015;1:13-9.

16. Carvalho LS, Meier S, Wang SW. Poverty and Economic Decision-Making: Evidence from Changes in Financial Resources at Payday. Am Econ Rev. 2016;106(2):260-84.

17. Schilbach F, Schofield H, Mullainathan S. The Psychological Lives of the Poor. Am Econ Rev. 2016;106(5):435-40.

18. Shah AK, Mullainathan S, Shafir E. Some Consequences of Having Too Little. Science. 2012;338(6107):682-5.

19. Beenackers MA, Oude Groeniger J, van Lenthe FJ, Kamphuis CBM. The role of financial strain and self-control in explaining health behaviours: the GLOBE study. Eur J Public Health. 2017;28(4):597-603.

20. Nudelman G, Ivanova $E$. The relationship between frequency of performance and perceived importance of health behaviours. J Health Psychol. 2018;1359105318770724.

21. Flycatcher. 2021 [cited 2021 Apr 6]. Available from: https://www.flyca tcher.eu/nl/

22. Van Loon AJM, Tijhuis M, Picavet HSJ, Surtees PG, Ormel J. Survey Non-response in the Netherlands: Effects on Prevalence Estimates and Associations. Ann Epidemiol. 2003;13(2):105-10.

23. Picavet HSJ. National health surveys by mail or home interview: effects on response. J Epidemiol Community Health. 2001;55(6):408-13.

24. CBS. Bevolking; onderwijsniveau; geslacht, leeftijd en migratieachtergrond. https://opendata.cbs.nl/statline/\#/CBS/nl/dataset/82275NED/ table?fromstatweb: CBS; 2020.

25. CBS. Klassen bruto inkomen, provincie, 2016-2018 [Internet]. 2019. Available from: https://www.cbs.nl/nl-nl/maatwerk/2019/46/klassen-brutoinkomen-provincie-2016-2018

26. Torssander J, Erikson R. Stratification and Mortality-A Comparison of Education, Class, Status, and Income. Eur Sociol Rev. 2010;26(4):465-74.

27. Stronks K, Hoeymans N, Haverkamp B, Hertog FRJ den, Bon-Martens MJH van, Galenkamp H, et al. Do conceptualisations of health differ across social strata? A concept mapping study among lay people. BMJ Open. 2018;8(4):e020210.

28. Shipp AJ, Edwards JR, Lambert LS. Conceptualization and measurement of temporal focus: The subjective experience of the past, present, and future. Organ Behav Hum Decis Process. 2009;110(1):1-22. 
29. Luhmann M, Hawkley LC, Cacioppo JT. Thinking About One's Subjective Well-Being: Average Trends and Individual Differences. J Happiness Stud. 2014;15(4):757-81.

30. Richards L, Paskov M. Social class, employment status and inequality in psychological well-being in the UK: Cross-sectional and fixed effects analyses over two decades. Soc Sci Med. 2016;1:45-53.

31. Kuha J. AIC and BIC:Comparisons of Assumptions and Performance. Sociol Methods Res. 2004;33(2):188-229.

32. Bakk Z, Tekle FB, Vermunt JK. Estimating the Association between Latent Class Membership and External Variables Using Bias-adjusted Three-step Approaches. Sociol Methodol. 2013;43(1):272-311.

33. Petersen J, Bandeen-Roche K, Budtz-Jørgensen E, Groes Larsen K. Predicting Latent Class Scores for Subsequent Analysis. Psychometrika. 2012;77(2):244-62.

34. Linzer DA, Lewis JB. poLCA: An R Package for Polytomous Variable Latent Class Analysis. 2011. 2011th-06-14th ed. 2011;42(10):29.

35. Nguyen TQ, Webb-Vargas Y, Koning IM, Stuart EA. Causal Mediation Analysis With a Binary Outcome and Multiple Continuous or Ordinal Mediators: Simulations and Application to an Alcohol Intervention. Struct Equ Model Multidiscip J. 2016;23(3):368-83.

36. Zhao X, Lynch JG Jr, Chen Q. Reconsidering Baron and Kenny: Myths and Truths about Mediation Analysis. J Consum Res. 2010;37(2):197-206.

37. Muthen L, Muthen B. Mplus. Los Angeles, CA; 2017.

38. Garthwaite K, Bambra C. How the other half live": Lay perspectives on health inequalities in an age of austerity. Soc Sci Med. 2017;1:268-75.

39. Romeo-Velilla M, Ellis N, Hurst G, Grogan S, Gidlow C. A qualitative study of disengagement in disadvantaged areas of the UK: 'You come through your door and you lock that door.' Health Place. 2018;1:62-9.

40. Körner A, Reitzle M, Silbereisen RK. Work-related demands and life satisfaction: The effects of engagement and disengagement among employed and long-term unemployed people. J Vocat Behav. 2012;80(1):187-96.

41. Dieckhoff M, Gash V. Unemployed and alone? Unemployment and social participation in Europe. Int J Sociol Soc Policy. 2015;35(1/2):67-90.

42. McLarnon MJW, O'Neill TA. Extensions of Auxiliary Variable Approaches for the Investigation of Mediation, Moderation, and Conditional Effects in Mixture Models [Supplementary material p.25]. Organ Res Methods. 2018;21(4):955-82.

43. Asparouhov T, Muthén B. Auxiliary Variables in Mixture Modeling: Three-Step Approaches Using Mplus. Struct Equ Model Multidiscip J. 2014;21(3):329-41.

\section{Publisher's Note}

Springer Nature remains neutral with regard to jurisdictional claims in published maps and institutional affiliations.

Ready to submit your research? Choose BMC and benefit from:

- fast, convenient online submission

- thorough peer review by experienced researchers in your field

- rapid publication on acceptance

- support for research data, including large and complex data types

- gold Open Access which fosters wider collaboration and increased citations

- maximum visibility for your research: over 100M website views per year

At BMC, research is always in progress.

Learn more biomedcentral.com/submissions 